\title{
Enhanced Photovoltaic Power Model Fidelity Using On-Site Irradiance and Degradation-Informed Performance Input
}

\author{
Matthew Dzurick, B.G. Potter, Jr., William F. Holmgren, and Kelly Simmons-Potter \\ University of Arizona, Tucson, AZ, 85721, USA
}

\begin{abstract}
The impact of irradiance data collection location and degradation-informed module performance on irradiance-topower model accuracy is evaluated. A decrease in RMSE of over $\mathbf{2 0 \%}$ is found for output power predictions using NREL PVWatts when site-specific irradiance data are coupled with maximum power point output characteristics obtained using accelerated lifecycle testing.
\end{abstract}

Index Terms - solar power generation, forecasting, degradation, photovoltaic cells

\section{INTRODUCTION}

Increased accuracy in photovoltaic (PV) power prediction is critical to the large-scale application of these technologies for both grid-tied utility energy production and distributed power generation. Higher fidelity forecast modeling provides an opportunity for better management of energy resources and offers an improved assessment of the long-term cost of investment in renewable energy generation. In this context, several irradiance-to-power (I-P) prediction models are readily available. Given access to atmospheric modeling and local irradiance prediction, I-P models represent an integral link toward the prediction of PV module output. In addition to input irradiance, these models require local environmental conditions (ambient and/or module temperature), installation conditions (e.g. mounting specifics, fixed vs. tracking), and modulespecific performance parameters (e.g. DC output voltage at maximum power point $\left(\mathrm{V}_{\mathrm{dcmp}}\right)$, short circuit current $\left(\mathrm{I}_{\mathrm{sc}}\right)$, temperature derating). The location of the environmental data collection site relative to the module or string under consideration and the potential for time-dependent changes in module performance arising from degradation phenomena therefore can impact the predictive accuracy of I-P models. Clearly, location-specific weather data and field-relevant PV degradation behavior could be expected to produce greater accuracy in the model output.

The present study examines both the impact of on-site vs. remote irradiance data sources and the use of module degradation behavior on irradiance-to-power model performance. Field-testing and environmental chamber-based PV performance results coupled with local environmental and irradiance inputs are used to evaluate the effect of such location-specific and module-specific data on the accuracy of the NREL PVWatts I-P model performance as applied to a commercially available multicrystalline $\mathrm{Si} \mathrm{PV}$ module technology. We find that the availability of locally-collected irradiance data, coupled with an understanding of degradationdependent PV performance behavior results in a decrease in NREL PVWatts output power RMSE of over $20 \%$.

\section{EXPERIMENTAL METHODS}

A two-panel string of multicrystalline $\mathrm{Si}$ modules was installed on fixed, open frames at the Tucson Electric Power/Arizona Research Institute for Solar Energy (TEP/AzRISE) solar test yard (Tucson, AZ). Modules were deployed in April, 2017.

DC power output and backside temperatures (Type-T thermocouples, standard IES three-sensor arrangement per module) were collected every minute using a CR1000 data logger (Campbell Scientific, Inc.). Environmental and irradiance conditions were also recorded at 1 minute intervals at the test yard throughout the testing period using a locally sited, autonomous weather/irradiance station (Smart Solar Field (SOFIE)) pictured in Figure 1. Collected data included DNI (Direct Normal Irradiance), DHI (Diffuse Horizontal Irradiance), GHI (Global Horizontal Irradiance), POA (Plane of Array) Irradiance, wind speed, wind direction, and ambient temperature. In addition, data from an NREL Measurement and Instrumentation Data Center (MIDC) - the Observed Atmospheric and Solar Information System (OASIS) [1] located approximately 5.6 miles from the test yard at the University of Arizona was used to obtain minute-to-minute irradiance and weather information for comparison.

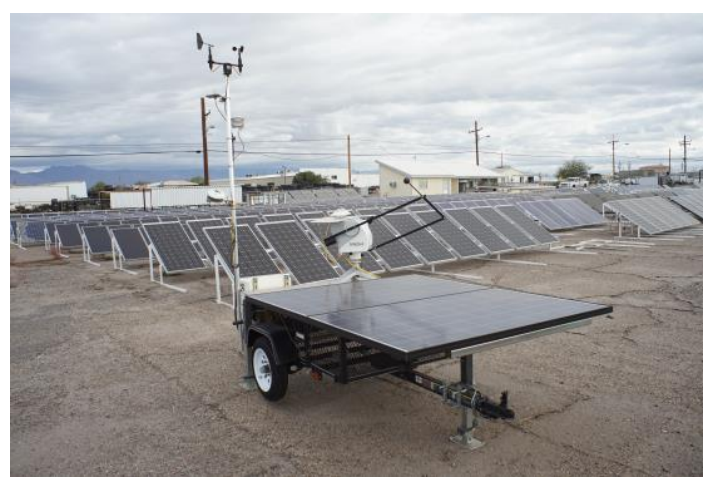

Fig. 1: Autonomous Solar Field (SOFIE) measurement station located at the TEP/AzRISE solar test yard in Tucson, AZ. 
Insight into performance degradation contributions to module output and modeling was aided by Accelerated Lifecycle Testing (ALT) of another (identical) multicrystalline Si PV panel subjected to Tucson, AZ temperature, relative humidity and irradiance conditions consistent with those recorded at the test yard site over the time frame used in the field test. These latter tests were performed in a walk-in environmental chamber providing controlled temperature, relative humidity and single-sun irradiance conditions. The associated tests and resulting data for these accelerateddegradation experiments have been reported previously [2].

\section{IRRADIANCE-TO-POWER MODELING}

Vendor-provided module performance metrics (temperature de-rating, maximum power point output voltage $\left(\mathrm{V}_{\mathrm{dcmp}}\right)$ ) as well as degradation-informed $\mathrm{V}_{\mathrm{dcmp}}$ after ALT were combined with either SOFIE or OASIS-derived weather and irradiance data to model DC power output using the NREL-developed PVWatts model [3]. In the present work, the pvlib-python implementation of the PVWatts model was used [4]. PVWatts enables the computation of anticipated DC power output from a PV module (developed for crystalline $\mathrm{Si}$ ) using the following relationship:

$$
P_{d c}=\frac{E_{e f f}}{E_{0}} P_{d c 0}\left(1+\gamma_{p d c}\left(T_{c e l l}-T_{r e f}\right)\right)
$$

where: $\mathrm{P}_{d c}=$ maximum power point (DC); $\mathrm{E}_{\text {eff }}=$ the effective (plane-of-array) irradiance value; $\mathrm{E}_{o}=$ reference irradiance $=$ $1000 \mathrm{~W} / \mathrm{m}^{2}$. $\quad \mathrm{P}_{d c 0}=$ maximum power point (DC) under reference conditions $=270 \mathrm{~W}$ per panel (vendor-supplied); $\gamma_{\mathrm{pdc}}$ $=$ temperature derating factor for the module $=-0.0039$ (vendorsupplied); $\mathrm{T}_{\text {cell }}=$ cell temperature; $\mathrm{T}_{\text {ref }}=$ reference temperature $=25{ }^{\circ} \mathrm{C}$.

The module backside temperature $\left(T_{m}\right)$ was used to approximate $\mathrm{T}_{\text {cell }}$ for modeling purposes. $\mathrm{T}_{m}$ was obtained by direct, backside temperature measurement as described above or by using the Sandia module temperature model [5],

$$
T_{m}=E_{P O A} \cdot\left(e^{a+b \cdot W S}\right)+T_{a}
$$

where: $\mathrm{a}$ and $\mathrm{b}$ are constants for open-rack mounted glass/cell/polymer sheet construction, $\mathrm{WS}=$ wind speed, $\mathrm{T}_{a}=$ ambient temperature $\left({ }^{\circ} \mathrm{C}\right)$.

Power output predictions for the 2-panel string were pursued using environmental and irradiance data collected from April, 2017 to April, 2018, i.e. year 1 of the field testing period. As part of a comprehensive investigation of the effect of model input source on PVWatts model fidelity, average errors between model output and measured, field-test data were examined over both month-long and day-long periods at different points of the seasonal cycle. In the present work, the impact of modeling parameter origin on the variation in prediction error was assessed in the context of two irradiance

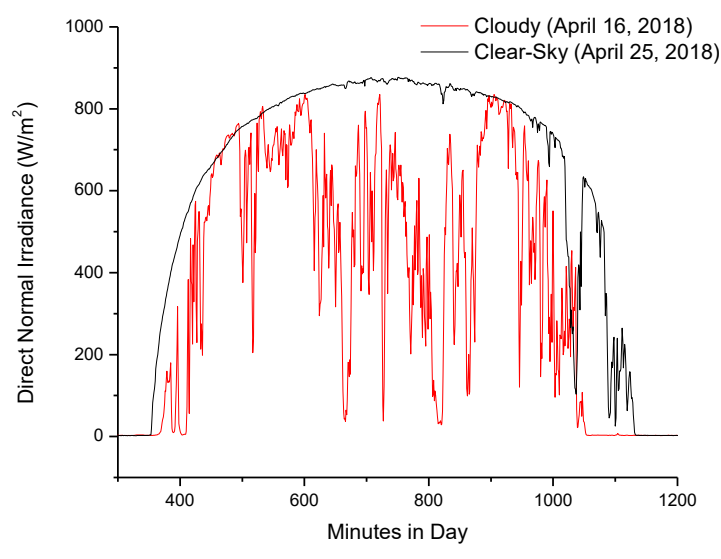

Fig. 2: Direct Normal Irradiance (DNI) on the two representative days that serve as the focus for the present study.

conditions: clear sky and intermittent clouds. Here, the impact of the origin of the environmental and irradiance input (SOFIE or OASIS) and the $\mathrm{P}_{d c o}$ value (vendor-supplied or degradationinformed) used in PVWatts was examined.

\section{RESULTS AND DISCUSSION}

A clear day (April 25) and a variable cloudy day (April 16) were selected for examination in the present study. Figure 2 contains direct normal irradiance (DNI) data for these two days. The resulting model behavior and associated errors are representative of similar spring/summer days within the yearlong measurement period and serve to highlight the relative impacts of environmental data source location and degradation contribution to the predictive capability of the PVWatts I-P model under these characteristic irradiance conditions.

\section{A. Effect of irradiance data origin}

Figure 3 (upper) contains modeled DC output power using remote environmental and irradiance measurement input (OASIS) for the clear day example (April 25). Figure 3 (lower) depicts modeled results for that day based on local, site-specific environmental and irradiance input (SOFIE). Both Figures also contain the measured output power from the 2-panel string. A consistent overestimate of observed output power is returned by the model. The corresponding RMSE values over the period were $8.4 \%$ and $9.2 \%$ (relative to maximum vendor-quoted panel output) for the use of OASIS and SOFIE irradiance data, respectively. In this case, the use of regional irradiance data from OASIS yielded a comparable power prediction to that obtained by applying location-specific irradiance data from SOFIE.

In contrast, the impact of environmental data collection proximity on power prediction under cloudy conditions (April 

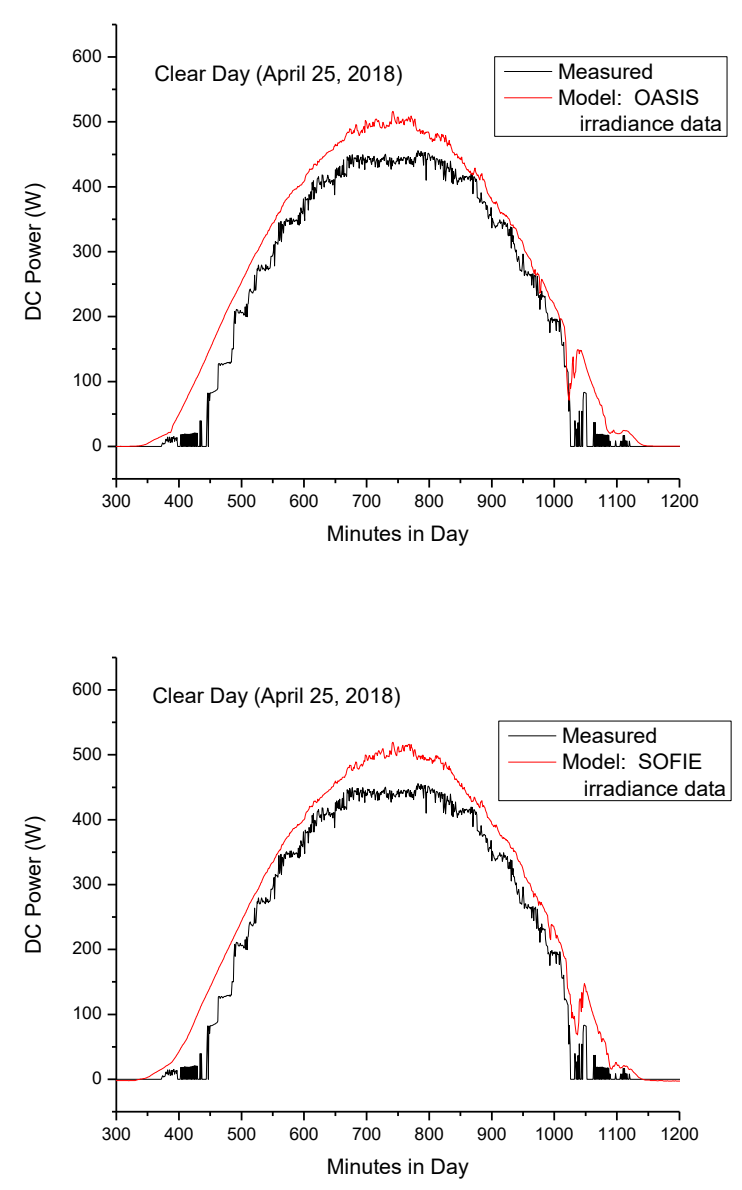

Fig. 3: Comparison of NREL PVWatts model (red) and measured power output (black) using OASIS irradiance data (upper graph) and SOFIE irradiance data (lower graph) for a representative clear sky day.

15) is illustrated in Figures 4. Again, a consistent overestimate of the output power is returned by the model.

In this case, however, local cloud cover variation between the data collection site and the string location is seen to significantly impact minute-to-minute irradiance conditions. Figure 4 (upper) exhibits significant discrepancies between predicted and measured power output throughout the daytime period associated with differences in local irradiance between the OASIS site and the module location. The result is an increase in RMSE for the predicted power of over $22 \%$ when using environmental and irradiance data collected from the offsite OASIS location. In contrast, the use of on-site irradiance data offers significant enhancement in the model's ability to follow the more rapidly evolving irradiance variation for the cloudy day example, resulting in the closer agreement between modeled and measured power output. The corresponding RMSE when using on-site irradiance data is significantly improved to $13 \%$.
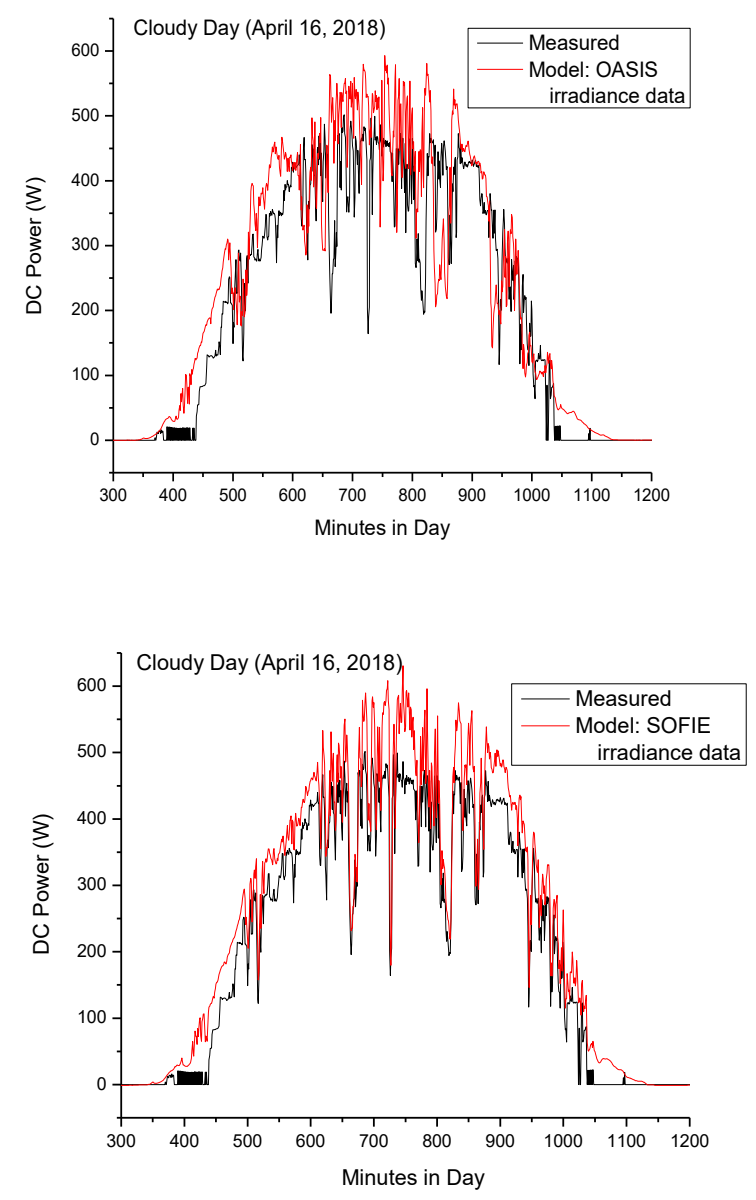

Fig. 4: Comparison of PVWatts model (red) and measured power output (black) using OASIS irradiance data (upper graph) and SOFIE irradiance data (lower graph) for a representative cloudy day.

To better visualize the impact of irradiance data source in the context of both clear-sky and cloudy irradiance conditions, Figure 5 contains minute-by-minute percentage output power prediction errors. While the computed errors closely track each other throughout the day for the two irradiance inputs on the clear sky day (Figure 5 (upper)), the sensitivity of irradiance sensor location relative to the test string location is clearly evident under cloudy sky conditions (Figure 5 (lower)). In this case, dramatic swings in prediction error are readily observed when remote irradiance sensor data is included in the model (OASIS data). By contrast, the use of local irradiance data as model input to PVWatts, suppresses large error transients throughout the day. 

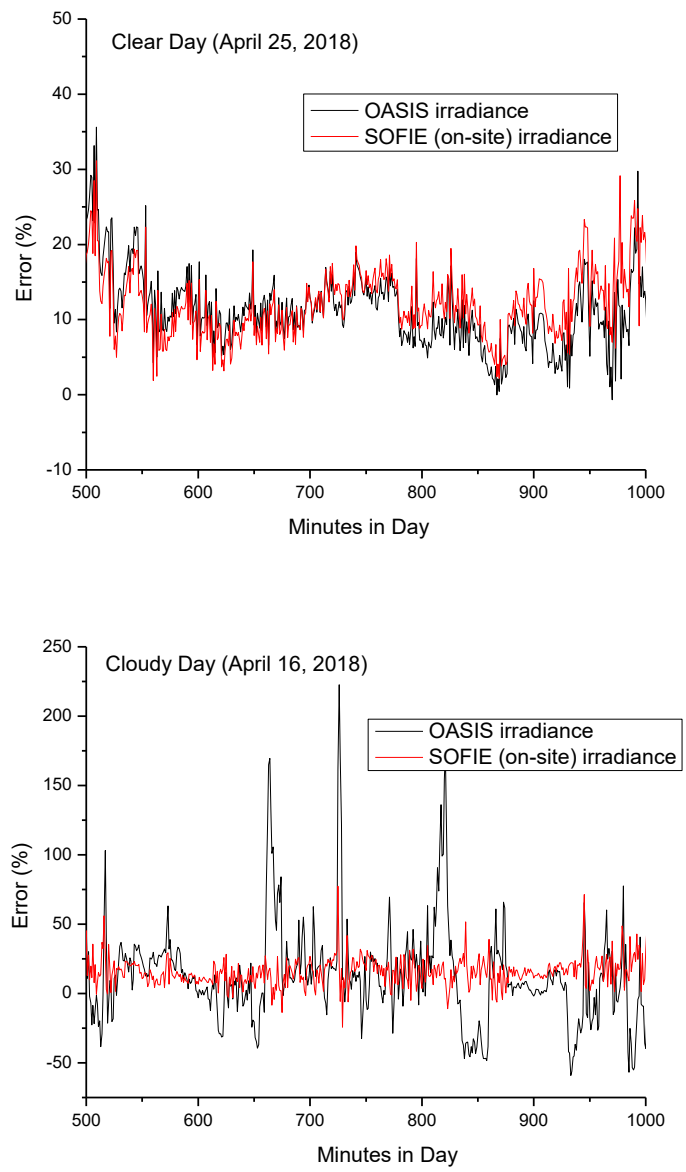

Fig. 5: Comparison of percentage error between measured DC power output and the PVWatts model prediction using different irradiance input data sources - OASIS (remote) and SOFIE (on-site). The relative impact of irradiance input source has a significant impact on modelled power prediction under cloudy conditions (lower graph).

\section{B. Effect of degradation-informed module performance characteristics}

The $\mathrm{P}_{d c o}$ parameter in the above analyses was taken to be the value quoted by the vendor, i.e. $\mathrm{P}_{d c o}=270 \mathrm{~W}$ per panel. However, after a single year of environmental exposure, a degradation in module performance is anticipated. Indeed, ALT of an identical multicrystalline $\mathrm{Si}$ module reveals a reduction in the observed $\mathrm{P}_{d c o}$ after a simulated one-year environmental exposure to Tucson temperature, relative humidity, and cumulative irradiance conditions [6]. In this case, the ALT-determined $\mathrm{P}_{d c o}$ was found to be $228.3 \mathrm{~W}$ per panel after a simulated one-year exposure cycle [2].

Figure 6 contains predicted and measured output power for both the clear and cloudy days described above, in this case using the degradation-informed, $\mathrm{P}_{d c o}$ parameter value in the PVWatts model. These data utilized the on-site (SOFIE)
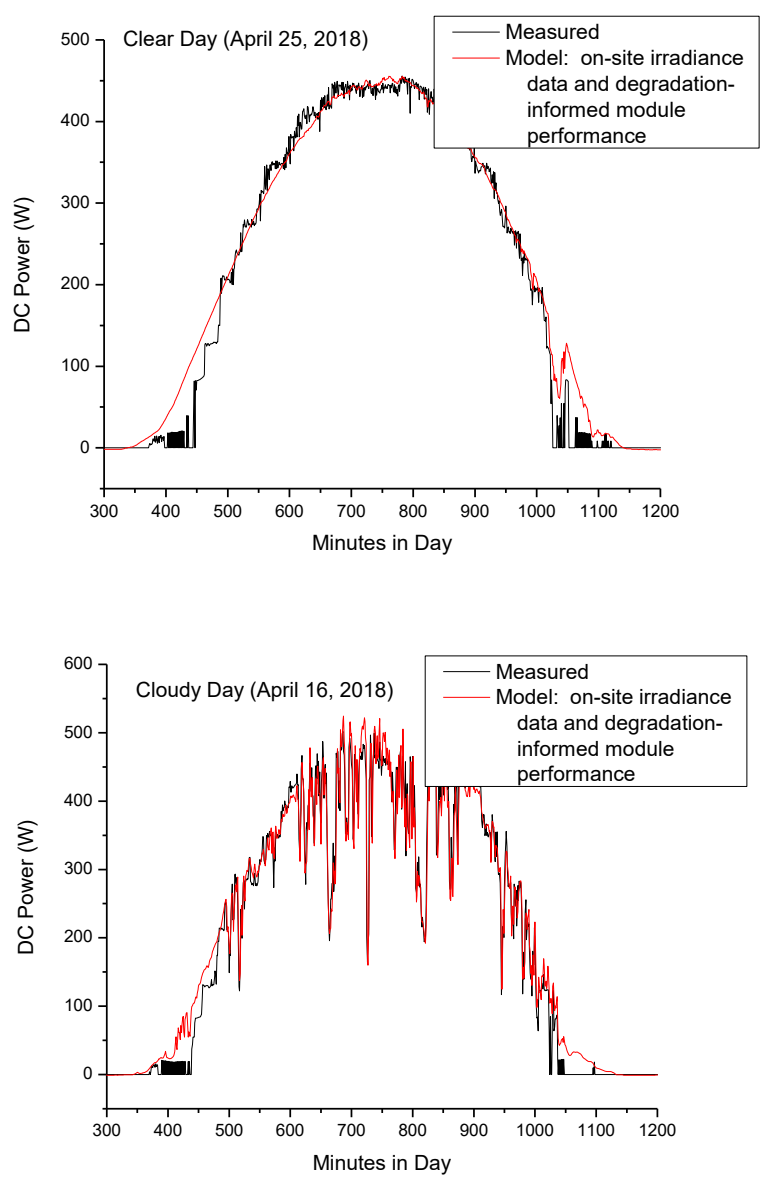

Fig. 6: Comparison of PVWatts model (red) and measured power output (black) using SOFIE irradiance data and degradation-informed Pdco parameter under clear sky (upper graph) and cloudy sky (lower graph) conditions.

irradiance source for the prediction of output power. Under these conditions, there was a further improvement in agreement between modeled and experimental output that is also observed in the percentage errors plotted in Figure 7. The use of both onsite irradiance data and degradation-informed module performance characteristics provides a more consistent agreement between model and experiment while reducing the RMSE to $2.1 \%$ and $5.7 \%$ for the clear and cloudy weather conditions, respectively.

\section{CONCLUSIONS}

Clearly, the proximity of irradiance data collection to PV generating installations can have a strong impact on the sensitivity of modeled power output to local transients in weather and cloud cover. In the present work, a spatial separation of approximately 5.6 miles resulted in significant discrepancies between modeled and measured PV output that were exacerbated by variable cloud cover. The current effort 


\section{ACKNOWLEDGEMENTS}

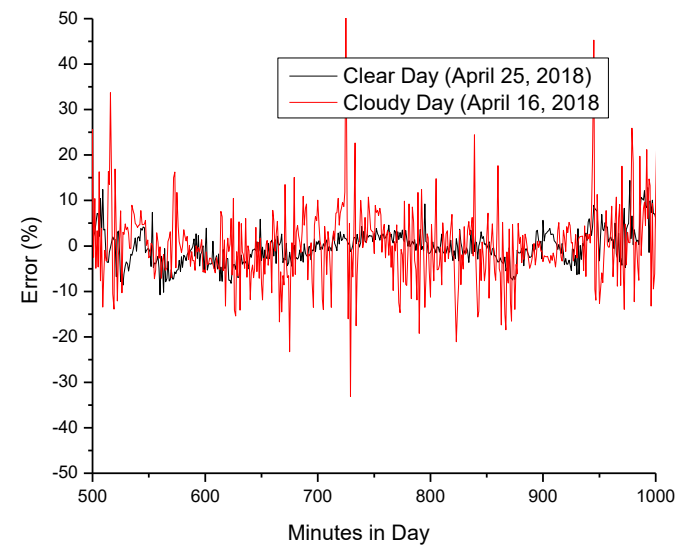

Fig. 7: Percentage error between measured DC power output and the PVWatts model prediction using SOFIE irradiance data and the degradation-informed $\mathrm{P}_{\mathrm{dco}}$ parameter under clear sky (black curve) and cloudy sky (red curve) conditions.

also includes degradation influences on module performance parameters within an I-P context. In this case, the inclusion of degradation effects on the module maximum power point output parameter was found to decrease RMSE from approximately $9 \%$ in the uninformed model to as little as $2.1 \%$ in the degradation-informed model under clear sky conditions. This study highlights the potential for the use of a degradationinformed model parameter to increase model fidelity throughout the module lifetime. Moreover, it points to the impact of using field-test data associated with performance loss to directly inform power models. Such information obtained from an existing solar array could then be directly applied to offer increased model accuracy for future installation planning.
This work was supported by Tucson Electric Power (TEP) Company, AzRISE, and the University of Arizona Institute for Energy Solutions (IES) under state of Arizona TRIF funds.

\section{REFERENCES}

[1] A. Andreas and S. Wilcox, "Observed Atmospheric and Solar Information System (OASIS); Tucson, Arizona (Data)," NREL Report No. DA-5500-56494. http://dx.doi.org/10.5439/1052226

[2] T. Lai, B. G. Potter, and K. Simmons-Potter, "Analysis of twelvemonth degradation in three polycrystalline photovoltaic modules," Proc. SPIE, vol. 9938, pp. 993800 1-9, 2016.

[3] A. P. Dobos, "PVWatts Version 5 Manual." [online]. Available: http://pvwatts.nrel.gov/downloads/pvwattsv5.pdf [Accessed January 21, 2019].

[4] William F. Holmgren, Clifford W. Hansen, and Mark A. Mikofski. "pvlib python: a python package for modeling solar energy systems.” Journal of Open Source Software, 3(29), 884, (2018). https://doi.org/10.21105/joss.00884

[5] D. L. King, W. E. Boyson, and J. A. Kratochvil, "Photovoltaic array performance model," Sandia Rep., vol. 3535, pp. 1-19, 2004.

[6] T. Lai, B. G. Potter, Jr. and K. Simmons-Potter, "Comparison of Efficiency Degradation in Polycrystalline-Si and CdTe ThinFilm PV Modules via Accelerated Lifecycle Testing," Proc. SPIE, Vol. 10370, pp. 103700J-1 - 103700J-8, 2017. 